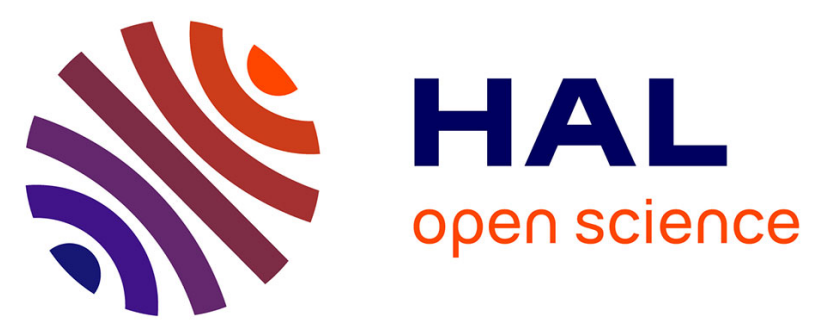

\title{
Theoretical and empirical approaches to understanding the effect of phosphonate groups on the thermal degradation for two chemically modified PMMA
}

Hossein Vahabi, Laurent Ferry, Claire Longuet, Rodolphe Sonnier, Claire

Negrell, Ghislain David, José-Marie Lopez-Cuesta

\section{To cite this version:}

Hossein Vahabi, Laurent Ferry, Claire Longuet, Rodolphe Sonnier, Claire Negrell, et al.. Theoretical and empirical approaches to understanding the effect of phosphonate groups on the thermal degradation for two chemically modified PMMA. European Polymer Journal, 2012, 48 (3), pp.604-612. 10.1016/j.eurpolymj.2011.12.015 . hal-00674367

\section{HAL Id: hal-00674367 https://hal.science/hal-00674367}

Submitted on 9 Jul 2021

HAL is a multi-disciplinary open access archive for the deposit and dissemination of scientific research documents, whether they are published or not. The documents may come from teaching and research institutions in France or abroad, or from public or private research centers.
L'archive ouverte pluridisciplinaire HAL, est destinée au dépôt et à la diffusion de documents scientifiques de niveau recherche, publiés ou non, émanant des établissements d'enseignement et de recherche français ou étrangers, des laboratoires publics ou privés. 


\title{
Theoretical and empirical approaches to understanding the effect of phosphonate groups on the thermal degradation for two chemically modified PMMA
}

\author{
Hossein Vahabi ${ }^{\text {a,b }}$, Laurent Ferry ${ }^{a}$, Claire Longuet ${ }^{\mathrm{a}, *}$, Rodolphe Sonnier ${ }^{\mathrm{a}}$, \\ Claire Negrell-Guirao ${ }^{\mathrm{b}}$, Ghislain David ${ }^{\mathrm{b}}$, José-Marie Lopez-Cuesta ${ }^{\mathrm{a}}$ \\ ${ }^{a}$ Centre de Recherche CMGD, Ecole des Mines d'Alès, 6 avenue de Clavières, F-30319 Alès Cedex, France \\ ${ }^{\mathrm{b}}$ Laboratoire d'Ingénierie et Architectures Macromoléculaires (IAM), Ecole Nationale Supérieure de Chimie de Montpellier (ENSCM), 8 rue de l'école normale, \\ 34296 Montpellier Cedex 5, France
}

\section{A B S T R A C T}

The influence of phosphonated groups on thermal degradation and flammability has been investigated in the case of two chemically modified PMMA. Thermogravimetric analysis as well as pyrolysis combustion flow calorimetry have been used to define the efficiency of phosphorus in both condensed and vapor phases. A theoretical study was also performed to determine the contribution of phosphonated groups to the effective heat of combustion, residue content and heat release capacity. Empirical and theoretical approaches agreed to highlight that PMMA modified with monophosphonated comonomer is more efficient in both condensed and vapor phases in terms of flammability and char formation. These results were attributed to the ability of phosphonate groups to interact with ester groups and also to the weakness of the $\mathrm{P}-\mathrm{C}-\mathrm{N}$ bonds. Moreover, this study proposes a method for designing the chemical environment of phosphonate group in polymers to achieve better flame retardancy.

Keywords:

PMMA

Phosphonated copolymers

Thermal stability

Flammability

\section{Introduction}

The physical and chemical incorporation of phosphorus flame retardant (PFR) into PMMA in order to improve its flammability have been investigated by several authors [1-3]. These works have highlighted the efficiency of chemical incorporation (i.e. via copolymerization) compared to physical incorporation of PFR in terms of PMMA flammability. Generally, the chemical incorporation (reactive approach, FR covalently attached to polymer chains) of FR has several advantages over the physical approach (additive). First, using the reactive approach avoids the problem of migration or blooming of FRs due to immobility of inherent FRs which stay within the polymer matrix. Secondly, a lower loading percentage of FR is needed

\footnotetext{
* Corresponding author. Tel.: +33 466785345; fax: +33 466785365.

E-mail address: claire.longuet@mines-ales.fr (C. Longuet).
}

compared to physical approach to obtain the same level of flame retardancy. Furthermore, a homogeneous dispersion of FR is possible at the molecular level using reactive approach [3]. Based on these results, we studied in a previous work the flammability of a PMMA chemically modified by an aminobisphosphonated comonomer [4]. This chemically modified PMMA presented a better thermal stability than that of pure PMMA and led to an important char formation (18\%). The results revealed the positive effect of phosphorus both in condensed and vapor phase that is beneficial for improving the thermal stability and flammability properties.

The present study consists of two parts: first in an empirical part, a comparison of a MMA-aminobisphosphonated copolymer (copo.(MMA-MANP2C3)) and a MMAmonophosphonated copolymer (copo.(MMA-MAPC1)), in terms of thermal stability and flammability properties, is reported. This part is mainly focused on determining the 


\section{Nomenclature}

\section{$X_{\text {char }} \quad$ char yield ( $\mathrm{g} / \mathrm{g}$ initial polymer)}

$X_{\text {Pini }} \quad$ initial phosphorus content ( $\mathrm{g} / \mathrm{g}$ initial polymer)

$X_{\text {Pcond }}$ phosphorus content in the condensed phase (g/ $\mathrm{g}$ initial polymer)

$X_{\text {Pvap }} \quad$ phosphorus content in the vapor phase (g/g initial polymer) $f_{\text {Pcond }} \quad$ fraction of phosphorus in the condensed phase (g/g initial phosphorus)

$f_{\text {Pvap }} \quad$ fraction of phosphorus in the condensed phase (g/g initial phosphorus) effect of phosphorus groups either in condensed or in vapor phase. The second part focuses on a theoretical study, based on the work of Lyon et al. [5], to determine the relationship between molecular structure and flammability of these copolymers and the efficiency of chemical groups on flame retardancy.

\section{Materials and methods}

Monophosphonated copolymer (Scheme 1c - named (copo.(MMA-MAPC1)) was prepared in three step reactions. First, dimethyl-a-hydroxymethylphosphonate was obtained from the reaction between dimethyl hydrogenophosphonate and paraformaldehyde in the presence of methanol and anhydrous $\mathrm{K}_{2} \mathrm{CO}_{3}$ (Scheme $2 \mathrm{a}$ ). In the second step, methacrylation of dimethyl-a-hydroxymethylphosphonate was carried out using methacrylic acid in presence of dicyclohexylcarbodiimide (DCCI) N,N-dimethyl-4-aminopyridine (DMAP) (Scheme $2 \mathrm{~b}$ ). The last step consists in radical copolymerization of methylmethacrylate (MMA) and dimethyl(methacryloxy)methyl phosphonate in chloroform at $70^{\circ} \mathrm{C}$ in presence of $2,2^{\prime}$-azobisisobutylonitrile (AIBN) (Scheme 2c). PMMA and two copolymers (Scheme 1) were synthesised via radical polymerization method. The synthesis of PMMA and copo.(MMA-MANP2C3) was described in a previous work [4]. The chemical structure of the products was assessed from ${ }^{1} \mathrm{H},{ }^{31} \mathrm{P}$ and ${ }^{13} \mathrm{C}$ NMR. In the case of the copolymers, the molar ratio between comonomers was fixed at 1:1. The phosphorus percentages are $12.7 \mathrm{wt} . \%$ and $10 \mathrm{wt} . \%$ for copo.(MMA-MANP2C3) and copo.(MMAMAPC1), respectively (calculated from NMR). The obtained phosphorus percentages using EDX analysis (at ambient temperature $13.7 \mathrm{wt} . \%$ and $10 \mathrm{wt} . \%$ for copo.(MMA-MAPC1) and copo.(MMA-MANP2C3), respectively) are closely similar to those measured from NMR analysis. The synthesis and characterization of samples were reported in details elsewhere [6,7].
Thermal gravimetric analysis (TGA) was carried out on a Perkin Elmer Pyris-1 instrument. The temperature range was from $50{ }^{\circ} \mathrm{C}$ to $900^{\circ} \mathrm{C}$ at a ramp rate of $10^{\circ} \mathrm{C} \mathrm{min}^{-1}$ under nitrogen and air atmosphere. Specimen weighed about $8 \mathrm{mg}$. This TGA instrument was coupled to a Fourier transform infrared spectrometer (FT-IR) (Bruker-IFS66) to analyze the evolved gases. (The heating rate and temperature range are identical to a simple TGA analysis). FT-IR measurements were carried out in the range of $4000-400 \mathrm{~cm}^{-1}$, with 8 scans and spectral resolution of $1 \mathrm{~cm}^{-1}$. The residues were directly observed using a Scanning Electron Microscopy (FEI Quanta 200 SEM). All images were obtained under high vacuum at a voltage of $15.0 \mathrm{kV}$ with a spot size of $2.8 \mathrm{~mm}$ and a working distance of $8.2 \mathrm{~mm}$. Analysis of the phosphorus percentage in char residue was performed by Energy Dispersive X-Ray spectroscopy (EDX) analysis using Oxford INCA Energy 300 system and a detector of $133 \mathrm{eV}$ resolution (at $\mathrm{Mn})$. The residues were collected from isothermal degradation in TGA analysis (under nitrogen) at different temperatures and then ground between two microscope glass slides for being homogeneous and compressed for forming a compact and smooth layer before analysis. Flammability results were obtained from Pyrolysis Combustion Flow Calorimeter (PCFC) instrument (FTT Company) (Specimen size $\sim 2-4 \mathrm{mg}$, heating rate $\left.=1 \mathrm{~K} \mathrm{~s}^{-1}\right)$. The Total Heat Release (THR) and Heat Release Capacity (HRC) values were obtained from this test (HRC is the sum of all peaks of heat release rate after deconvolution carried out with the FTT software).

These characterization methods were used to define thermal stability (TGA), flammability (PCFC) and efficiency of phosphorus in both condensed and vapor phases (EDX, TGA/FT-IR). Some analysis methods were specially used to analyze the condensed phase such as EDX (determining the percentage of phosphorus in residue) or vapor phase such as coupled TGA/FT-IR (determining the nature of evolved gases during the thermal degradation). Furthermore, it seems obvious that the comparison and matching

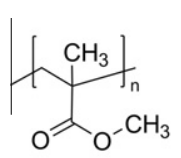

(a)

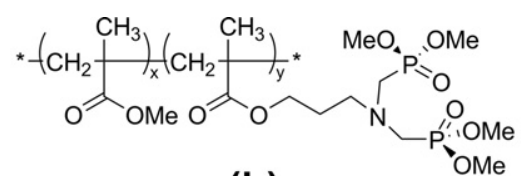

(b)

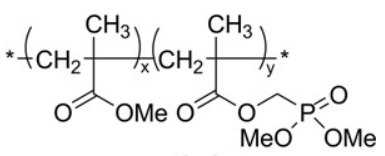

(c)

Scheme 1. Chemical formula of (a) pure PMMA, (b) aminobisphosphonated copolymer (copo.(MMA-MANP2C3)) and (c) monophosphonated copolymer (copo.(MMA-MAPC1)) ( $\mathrm{x}=\mathrm{y}$ stoichiometry determined by NMR ${ }^{1} \mathrm{H}$ ). 
(a)

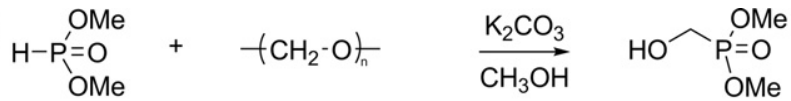

(b)<smiles>C=C(C)C(=C)O</smiles><smiles>C=C(C)C(=O)OCP(=O)(OC)OC</smiles>

(c)

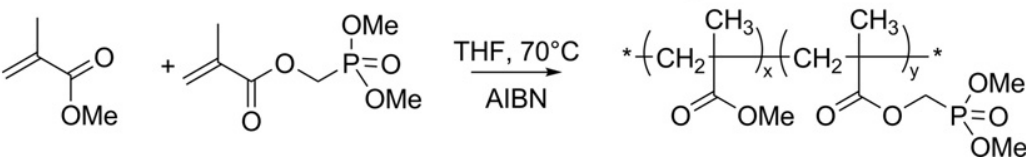

Scheme 2. Three-step synthesis of monophosphonated copolymer, copo.(MMA-MAPC1)[6].

of some results in one phase can provide useful information for the other phase (e.g. determining the percentage of phosphorus in condensed phase can provide the percentage of phosphorus in vapor phase).

\section{Results and discussion}

\subsection{Part A: empirical approach}

\subsubsection{Phosphorus effect in condensed phase (Residue analysis - SEM/EDX)}

Fig. 1 shows the TGA curves and corresponding derivate curves (DTG) of PMMA compared to monophosphonated copolymer (copo.(MMA-MAPC1)) and aminobisphosphonated copolymer (copo.(MMA-MANP2C3)) under inert atmosphere. According to other authors [8-11] the different steps of degradation of PMMA correspond to the different types of polymer chains obtained from radical polymerization. The first step of degradation (around $290^{\circ} \mathrm{C}$ ) takes place by scissions at unsaturated ends (resulting from termination by disproportionation) involving a homolytic $\beta$ scission to the vinyl group. The second step (around $390{ }^{\circ} \mathrm{C}$ ) is a random scission within the polymer chain.

In contrast to PMMA and copo.(MMA-MANP2C3), copo.(MMA-MAPC1) shows a different degradation pathway. The first and second stages of degradation of copo.(MMAMANP2C3) seem identical to PMMA. In the case of copo.(MMA-MAPC1) these stages are shifted to $330^{\circ} \mathrm{C}$ and $420^{\circ} \mathrm{C}$. The onset temperature $\left(285^{\circ} \mathrm{C}\right.$, determined at $5 \mathrm{wt} . \%$ of weight loss) of copo.(MMA-MAPC1) is higher than that of copo.(MMA-MANP2C3) $\left(238^{\circ} \mathrm{C}\right)$. However, the degradation rate of copo.(MMA-MAPC1) is faster than copo.(MMA-MANP2C3) (between $300{ }^{\circ} \mathrm{C}$ and $600{ }^{\circ} \mathrm{C}$ ). The char yield Xchar of copo.(MMA-MAPC1) (22 wt.\%) is slightly higher than that of copo.(MMA-MANP2C3) (18 wt.\%) and a stabilization of mass percentage is observed after $700{ }^{\circ} \mathrm{C}$ for copo.(MMA-MAPC1) (Table 1).

The fraction of phosphorus in residues $\left(X_{\text {Pcond }} / X_{\text {char }}\right)$ was determined using EDX analysis and presented in Fig. 2. Residues enrich in phosphorus as temperature increases. In the case of copo.(MMA-MANP2C3) residue, phosphorus content reaches a maximum around $430^{\circ} \mathrm{C}$.

From these latter results, the estimated thermogravimetric curve of (atomic) phosphorus can be calculated using the previously described method in Ref. [4]. This curve permits to follow the partition of phosphorus between condensed $f_{\text {Pcond }}$ and vapor phase $f_{\text {Pvap }}$ as a function of temperature. $f_{\text {Pcond }}$ is calculated using this formula:

$f_{\text {Pcond }}=\frac{X_{\text {char }} \frac{X_{\text {Pcond }}}{X_{\text {char }}}}{X_{\text {Pini }}}$

$f_{\text {Pvap }}=1-f_{\text {Pcond }}$

where $X_{\text {Pcond }} / X_{\text {char }}$ corresponds to the phosphorus fraction in residues quantitatively measured by EDX, $X_{\text {Pini }}$ corresponds to the initial phosphorus content measured by

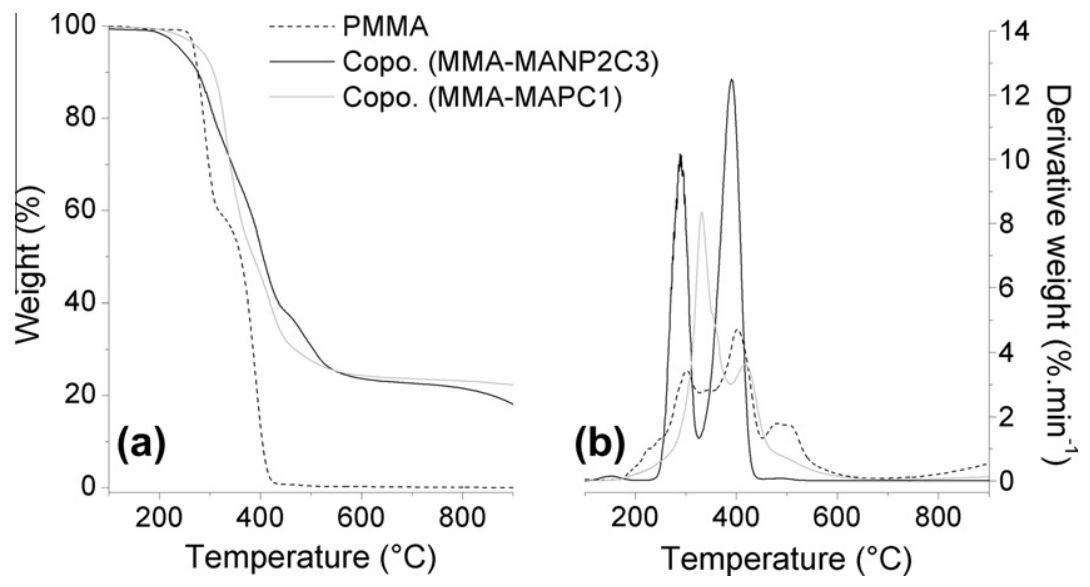

Fig. 1. TGA (a) and DTG (b) curves for pure PMMA, copo.(MMA-MANP2C3) and copo.(MMA-MAPC1) at a heating rate of $10^{\circ} \mathrm{C} \mathrm{min}{ }^{-1} \mathrm{under}^{\circ}$ nitrogen. 
Table 1

TGA parameters of pure PMMA, copo.(MMA-MANP2C3) and copo.(MMAMAPC1) under nitrogen atmosphere.

\begin{tabular}{lllllc}
\hline Composition & $\begin{array}{l}\text { Phosphorus } \\
(\text { wt.\%) }\end{array}$ & $\begin{array}{l}\mathrm{T}_{5 \%} \\
\left({ }^{\circ} \mathrm{C}\right)\end{array}$ & $\begin{array}{l}\mathrm{T}_{10 \%} \\
\left({ }^{\circ} \mathrm{C}\right)\end{array}$ & $\begin{array}{l}\mathrm{T}_{50 \%} \\
\left({ }^{\circ} \mathrm{C}\right)\end{array}$ & $\begin{array}{l}X_{\text {char }} \\
(\text { wt.\%) })^{* *}\end{array}$ \\
\hline $\begin{array}{l}\text { PMMA } \\
\text { Copo(MMA- } \\
\text { MANP2C3) }\end{array}$ & 12.7 & 270 & 274 & 362 & 0 \\
$\begin{array}{c}\text { Copo(MMA- } \\
\text { MAPC1) }\end{array}$ & 10 & 238 & 274 & 407 & 18 \\
& & 285 & 311 & 387 & 22 \\
\hline
\end{tabular}

Measured by NMR.

** Char yield at $900{ }^{\circ} \mathrm{C}$.

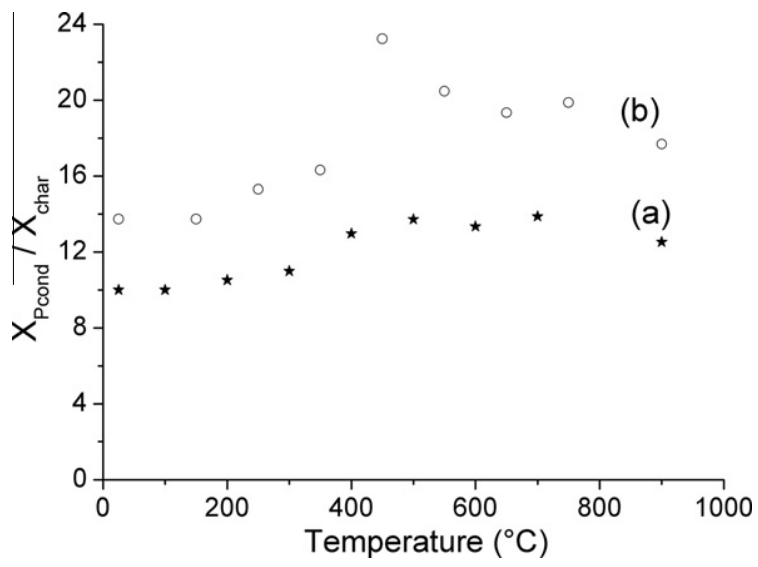

Fig. 2. Phosphorus fraction in residue during TGA test for copo.(MMAMAPC1) (a) and comparison of this result with that of copo.(MMAMANP2C3) (b).

EDX (13.7 wt.\% and 10 wt.\% for copo.(MMA-MANP2C3) and copo.(MMA-MAPC1), respectively).

Fig. 3 shows calculated thermogravimetric curves (a) and their corresponding derivatives (b) for atomic phosphorus, thermogravimetric curves of copolymers have been superposed for comparison.

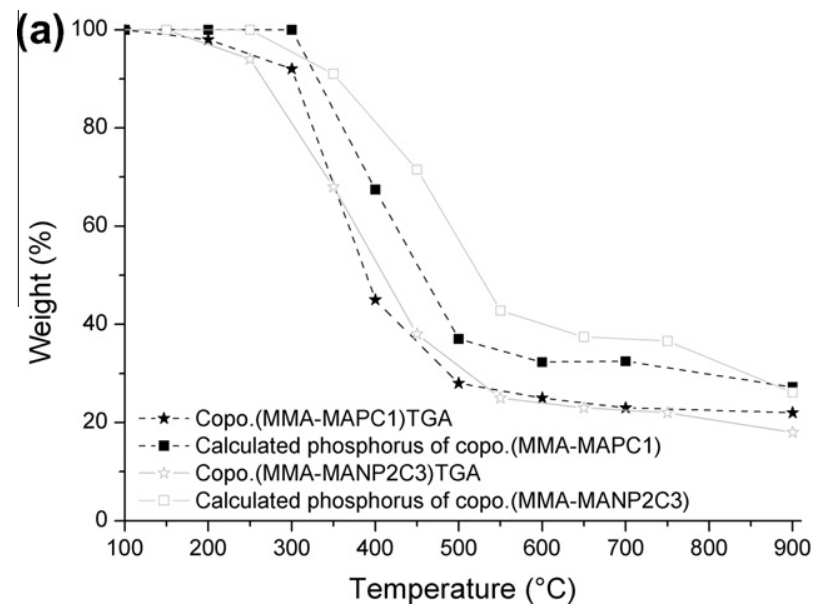

Fig. 3a indicates that the fraction of phosphorus remaining in the residue $\left(f_{\text {Pcond }}\right)$ is higher for copo.(MMAMANP2C3) than for copo.(MMA-MAPC1), 36\% against 31\% at $750{ }^{\circ} \mathrm{C}$. Paradoxically, the ability of copo.(MMAMANP2C3) to promote charring appears lower than that of copo.(MMA-MAPC1), as measured from TGA test and highlighted in Table 1 . Therefore, a good indicator of the efficiency to promote charring can be obtained, thanks to normalization, by dividing the percentage of char by the percentage of phosphorus in the condensed phase.

Charring Efficiency of Phosphorous(CEP)

$$
=\frac{X_{\text {char }}(\text { copo })-X_{\text {char }}(\text { PMMA })}{f_{\text {Pcond }} \times X_{\text {Pini }}}
$$

Calculating this ratio leads to $4.46 \%$ char $/ \% \mathrm{P}$ and 7.74\%char/\%P for copo.(MMA-MANP2C3) and copo.(MMAMAPC1), respectively (Table 2). These results clearly show that phosphonate groups of copo.(MMA-MAPC1) have a higher ability to promote char formation than those of copo.(MMA-MANP2C3).

A possible hypothesis to explain these data could be that the phosphonate groups may interact more easily with ester groups of PMMA, in the case of copo.(MMA-MAPC1). These interactions lead to a thermal stabilization of the copo.(MMA-MAPC1) as proved by the shift of the first peak of degradation (Fig. 1, at $330^{\circ} \mathrm{C}$ ) and by a higher char residue (Table 1). Conversely, in the case of copo.(MMA-MANP2C3), phosphonate groups may interact preferentially between themselves because of the "claw-like" conformation and there will be less interaction between phosphonate groups and ester groups of PMMA. Thus, the degradation steps are similar to those of PMMA (1st and 2nd steps), except at high temperature $\left(460^{\circ} \mathrm{C}\right)$ where a third step of degradation occurs. Fig. 5b reveals that phosphorus is released in the vapor phase mainly in this range of temperature, contrary to copo.(MMA-MAPC1) where phosphorus is released around $380^{\circ} \mathrm{C}$. Interactions between phosphonate groups in copo.(MMA-MANP2C3) may explain the shift of phosphorus release to higher temperature.

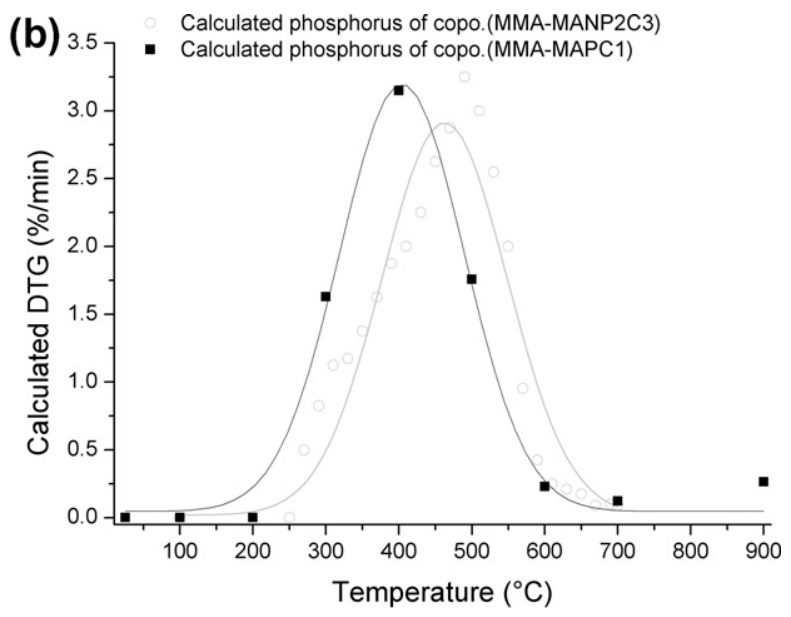

Fig. 3. Comparison of TGA curves and calculated phosphorus percentage curves (a), comparison of derivative curves of phosphorus percentage as a function of temperature for both copolymers (b). 
Table 2

Values of charring efficiency of phosphorus (CEP) for the two copolymers.

\begin{tabular}{lll}
\hline & Copo.(MMA-MANP2C3) & Copo.(MMA-MAPC1) \\
\hline CEP & 4.46 & 7.74 \\
\hline
\end{tabular}

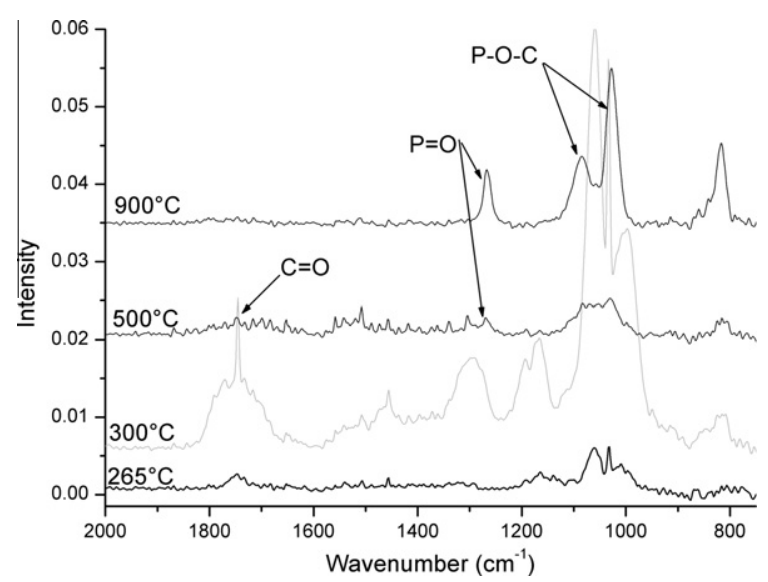

Fig. 4. Vapor phase FT-IR spectra at various temperatures during the thermal degradation of copo.(MMA-MAPC1).

\subsubsection{Phosphorus effect in vapor phase}

Similarly to condensed phase, the efficiency of phosphorus in the vapor phase could be assessed. TGA coupled to FT-IR spectroscopy is a very useful tool for probing the thermal degradation of polymers [12]]. In this study, it was essentially used to determine the presence of phosphorus in evolved gases and also the temperature of phosphorus release, during the degradation. These results helped us to understand the role of phosphorus during the thermal degradation.

In the above mentioned previous work, the evolved gases of copo.(MMA-MANP2C3) has been studied [4]. Fig. 4 shows the infrared spectrum (taken at $265^{\circ} \mathrm{C}$, $300^{\circ} \mathrm{C}, 500^{\circ} \mathrm{C}$ and $900^{\circ} \mathrm{C}$ ) of evolved gases from the degradation of copo.(MMA-MAPC1) in nitrogen. The FT-IR absorption bands between $1030 \mathrm{~cm}^{-1}$ and $1060 \mathrm{~cm}^{-1}$ (at $300^{\circ} \mathrm{C}$ ) can be attributed to $\mathrm{P}-\mathrm{O}-\mathrm{C}$ vibration. Other identified bands are $C=O\left(1740 \mathrm{~cm}^{-1}\right)$ and $\mathrm{P}=\mathrm{O}\left(1267 \mathrm{~cm}^{-1}\right)$.

Fig. 5 a presents the evolution of $\mathrm{P}-\mathrm{O}-\mathrm{C}, \mathrm{P}=\mathrm{O}$ and $\mathrm{C}=\mathrm{O}$ band intensities as a function of the temperature of the released products during the TGA analysis. The maximum values of $\mathrm{P}-\mathrm{O}-\mathrm{C}$ and $\mathrm{C}=\mathrm{O}$ release are reached around $360^{\circ} \mathrm{C}$. The release of $\mathrm{P}=\mathrm{O}$ begins around $450^{\circ} \mathrm{C}$ and gradually increased until the end of analysis $\left(900^{\circ} \mathrm{C}\right)$. The release of $\mathrm{P}=\mathrm{O}$ in this range of temperature is probably due to partial degradation of char residue.

The comparison of $\mathrm{P}-\mathrm{O}-\mathrm{C}$ band intensities as a function of temperature (Fig. 5b) showed that phosphorus species are released progressively between 250 and $450{ }^{\circ} \mathrm{C}$ in the case of copo.(MMA-MAPC1) whereas they mainly evolved at low temperature (around $250{ }^{\circ} \mathrm{C}$ ) and at high temperature (around $500^{\circ} \mathrm{C}$ ) in the case of copo.(MMA-MANP2C3).

The PCFC test is a suitable tool for assessing the flammability of small quantity (1-4 mg) of polymers. The Heat Release Rate (HRR) curves obtained from this test are shown in Fig. 6. Table 4 outlines that the THR and HRC parameters of phosphonated copolymers are largely lower than those of pure PMMA. Comparing copolymers enables to affirm that THR values are very similar. In order to highlight a possible effect of char residue on THR, the Effective Heat of Combustion (EHC) was determined. This parameter can be obtained from:

$\mathrm{EHC}=\frac{\mathrm{THR}}{\left(1-X_{\text {char }}\right)}$

The results indicate that EHC values are also very close for both copolymers.

The efficiency of phosphorus in the vapor phase (EPV) can be defined as the ratio of the decrease of EHC (Table 4) divided by the percentage of phosphorus in the gas phase:

Efficiency of Phosphorus in the Vapor phase(EPV)

$$
=\frac{E H C_{\text {PMMA }}-\mathrm{EHC}_{\text {copo }}}{f_{\text {Pvap }} \times X_{\text {Pini }} \times 100}
$$
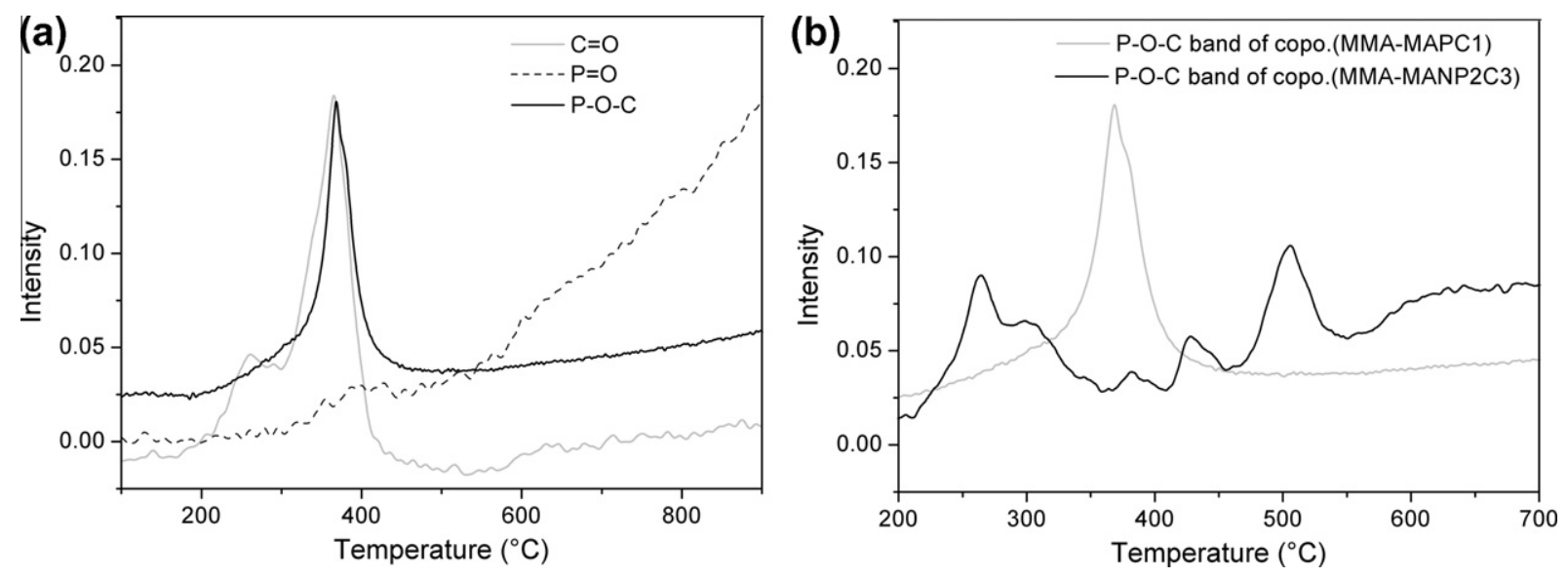

Fig. 5. (a) Gram-Schmidt curves as a function of temperature of copo.(MMA-MAPC1) at: $1026 \mathrm{~cm}^{-1}(\mathrm{P}-\mathrm{O}-\mathrm{C}), 1267 \mathrm{~cm}-1(\mathrm{P}=\mathrm{O}) \mathrm{and}^{-1740 \mathrm{~cm}}{ }^{-1}(\mathrm{C}=\mathrm{O}),(\mathrm{b})$ comparison between the P-O-C bands of copo.(MMA-MAPC1) and copo.(MMA-MANP2C3). 


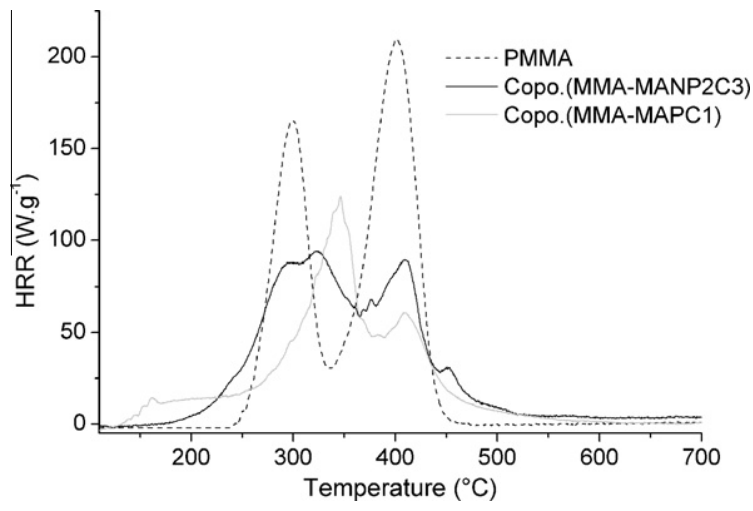

Fig. 6. HRR curves of pure PMMA, copo.(MMA-MANP2C3) and copo .(MMA-MAPC1).

Table 3

Values of efficiency of phosphorus in the vapor phase (EPV) for both copolymers.

\begin{tabular}{lll}
\hline & Copo.(MMA-MANP2C3) & Copo.(MMA-MAPC1) \\
\hline EPV & 0.669 & 0.698 \\
\hline
\end{tabular}

The results give the values of 0.669 and 0.698 $\mathrm{kJg}^{-1}(\%)^{-1}$ for copo.(MMA-MANP2C3) and copo.(MMAMAPC1), respectively (Table 3 ). Thus, on the whole, phosphonate groups of both copolymers seem to have similar efficiency in the vapor phase.

Finally the major difference between copolymers was found in HRC value which is significantly decreased in the case of copo.(MMA-MAPC1) (-15\% compared to copo.(MMA-MANP2C3)). The superposition of DTG and HRR curves of copolymers with DTG curve of atomic phosphorus is displayed in Fig. 7a (copo.(MMA-MAPC1)) and Fig. 7b (copo.(MMA-MANP2C3)). In the case of copo.(MMA-MAPC1), the similarity between DTG and HRR curves shows that the energetic value (HRR) of released gases is proportional to the quantity of released gases. It seems that the evolution of phosphorus species does not affect the HRR curve or the energetic value of vapor phase. Moreover, the derivative curve of phosphorus indicates that phosphorus is released all over the degradation process. HRR and DTG curves of copo.(MMA-MANP2C3) exhibits three peaks and peak of phosphorus in derivative curve is located around $500{ }^{\circ} \mathrm{C}$ (3rd peak). In this case, the phosphorus release occurs mainly at high temperature contrary to what was observed with copo.(MMA-MAPC1). Furthermore, in this temperature range, the HRR is not proportional to DTG. Thus, the difference in HRC values observed between copolymers (Table 4) may be attributed to the way phosphorus species are released. HRC decrease is more pronounced when phosphorus is released simultaneously with MMA and all over the degradation (case of MAPC1).

Indeed, it has been suggested that the simultaneous presence of nitrogen and phosphorus can lead to a synergistic action on flame retardancy of some polymers. The phosphorus-nitrogen combination has been extensively studied and reviewed in the literature $[13,14]$. Generally,
Table 4

Pyrolysis combustion flow calorimeter data.

\begin{tabular}{lllll}
\hline & $\begin{array}{l}\mathrm{HRC} \\
\left(\mathrm{Jg}^{-1} \mathrm{~K}^{-1}\right)\end{array}$ & $\begin{array}{l}\mathrm{THR} \\
\left(\mathrm{kJg}^{-1}\right)\end{array}$ & $\begin{array}{l}\mathrm{EHC} \\
\left(\mathrm{kJg}^{-1}\right)\end{array}$ & $\begin{array}{l}\mathrm{X}_{\text {char }}(\mathrm{wt} . \%) \text { at } \\
750{ }^{\circ} \mathrm{C}^{*}\end{array}$ \\
\hline $\begin{array}{l}\text { PMMA } \\
\begin{array}{c}\text { Copo.(MMA- } \\
\text { MANP2C3) } \\
\text { Copo.(MMA- } \\
\text { MAPC1) }\end{array}\end{array}$ & 2140 & 26 & 26 & 0 \\
& 181 & 15.7 & 20.1 & 22 \\
* & 16.1 & 21.2 & 24 \\
\hline Obtained from TGA under N2. & & & \\
\end{tabular}

the positive effect of such combination is observed when nitrogen and phosphorus atoms are chemically bonded. Nevertheless, we expected a similar positive effect from copo.(MMA-MANP2C3) as phosphorus and nitrogen are only separated from a methylene spacer. However, the above observed results prove the weakness of such chemical bond, thus inducing a lower efficiency for copo.(MMAMANP2C3) both in the condensed and in the vapor phase as compared to copo.(MMA-MAPC1), despite a lower phosphorus content.

In this first part, the flame retardant efficiency of phosphonate groups, in two different chemical environments, was calculated using an experimental approach. In the next part, the efficiency of phosphonate group will be calculated using a theoretical approach. This approach does not consider the interaction between chemical groups. It means that the contribution of phosphonate group to flammability properties should be similar for both copolymers. Therefore, if the contribution of phosphonate group, in both copolymers, is not similar, we could conclude that the chemical environment has an impact on flammability properties. In the future, this approach may be useful for chemists to determine the chemical structure of polymer in order to have the best efficiency of phosphonate groups.

\subsection{Part B: theoretical approach}

\subsubsection{Molecular structure and flammability relationship}

The flammability of a polymer is obviously related to its molecular structure. R. Lyon et al. $[5,15]$ have proposed to calculate the HRC (or sumHRC), EHC and residue percentage of some polymers according to Van Krevelen's approach [16]. Authors have determined the contributions to these properties for several chemical groups from eighty four polymers using PCFC test. The flammability properties of each polymer have been calculated using a theoretical method that consists in summing the molar contributions to HRC, EHC or residue percentage for the specific chemical groups of this polymer. The interactions between chemical groups were neglected. They found a quite good correlation between the calculated and measured values, even if great discrepancies were observed in some cases.

According to this method, we attempted to calculate the contributions to HRC, EHC and residue percentage of the phosphonate group studied in our work. The contributions of the phosphonate group were separately calculated for both copolymers (as represented in Scheme 3, the selected phosphonate groupe $\left(\mathrm{P}_{2} \mathrm{O}_{6}\right.$ and $\left.\left.\mathrm{PO}_{3}\right)\right)$. According to the approach of Lyon et al. [5], the contributions of the 

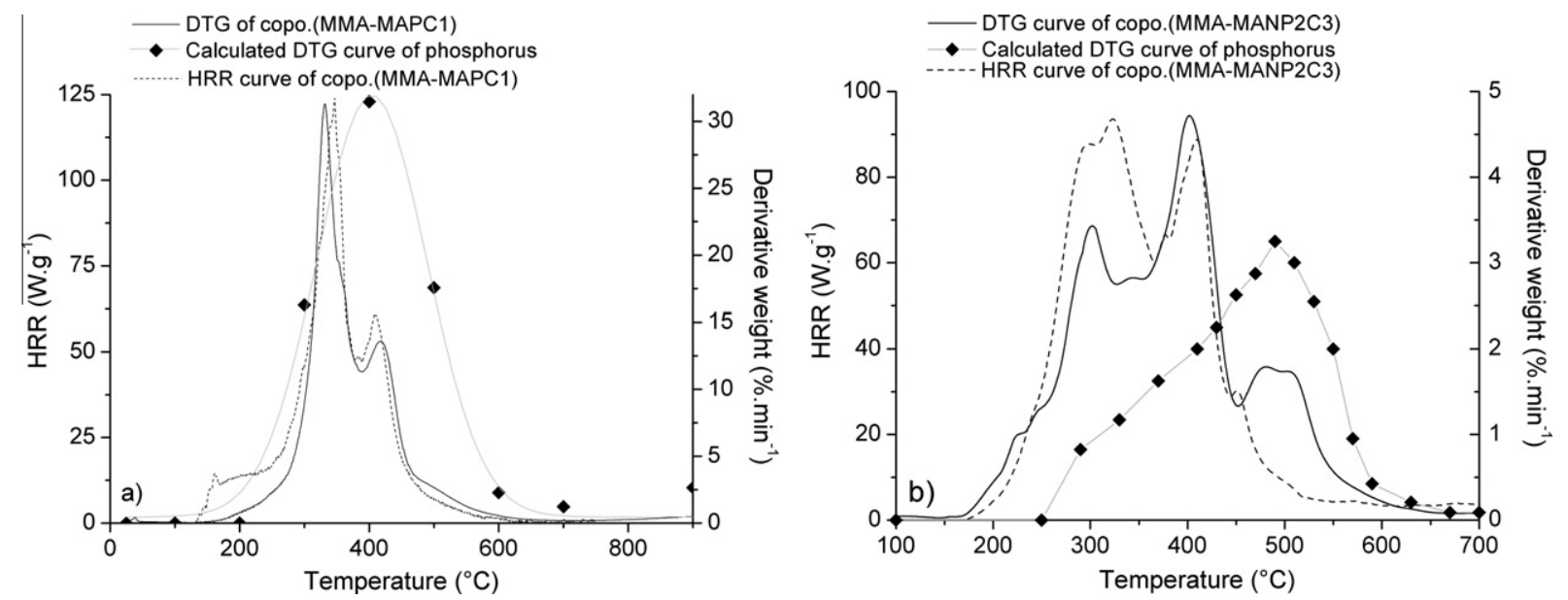

Fig. 7. Superposition of DTG and HRR curves with calculated DTG curve of atomic sidue for copo.(MMA-MAPC1) (a) and for copo.(MMA-MANP2C3) (b).
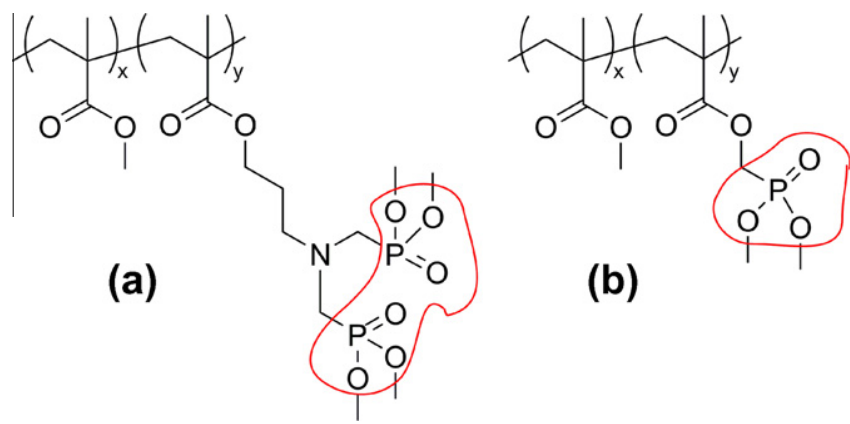

(b)

Scheme 3. Studied copolymers containing the phosphonate group, (a) copo.(MMA-MANP2C3) (b) copo.(MMA-MAPC1).

Table 5

Summary of results of PCFC tests and residue percentage at $750{ }^{\circ} \mathrm{C}$ in TGA analysis (N2) and EHC (calculated from THR and residue percentage).

\begin{tabular}{|c|c|c|c|c|c|}
\hline Molecule & Molecular weight of repetitive unit (g.mol $\left.{ }^{-1}\right)$ & $\operatorname{sumHRC}\left(\mathrm{Jg}^{-1} \mathrm{~K}^{-1}\right)$ & $\operatorname{THR}\left(\mathrm{kJg}^{-1}\right)$ & Residue at $750{ }^{\circ} \mathrm{C}(\%)$ & $\operatorname{EHC}\left(\mathrm{kJg}^{-1}\right)$ \\
\hline A & 100 & 400 & 24.4 & 0 & 24.4 \\
\hline A-1 & 387 & 193 & 14.3 & 29 & 20.1 \\
\hline A-2 & $244^{*}$ & 214 & 15.7 & 22 & 20.1 \\
\hline A-3 & $180^{*}$ & 220 & 16.9 & 19 & 20.9 \\
\hline A-4 & $108^{*}$ & 391 & 22.4 & 2.2 & 22.9 \\
\hline B-1 & 308 & 217 & 11.4 & 30 & 16.3 \\
\hline B-2 & $194^{*}$ & 181 & 16.1 & 23 & 20.9 \\
\hline
\end{tabular}

Equivalent molecular weight calculated according to the fractions of both comonomers.

phosphonate group should be similar for both copolymers. If it is not the case, we could conclude that the contributions to flammability properties of the phosphonate group depend on its chemical environment.

The database proposed by Lyon et al. [15] was used for the contributions of the other groups present in these copolymers (Table S1).

Pure homopolymers and five copolymers with different molar ratios of comonomers were synthesised and investigated (Copolymerization procedure is identical to the one described earlier in Section 2). All studied molecule structures are given in Table S2.

All samples were tested using PCFC apparatus and all data were summarized in Table 5 .
The contributions to HRC, EHC and residue content were chosen for the phosphorus-containing groups to fit well the experimental data (Figs. 8-10) - (Details of calculation in Supporting data-S3).

A quite good correlation is obtained between experimental and calculated values, in particular for residue content and EHC properties. Discrepancy is higher for sumHRC. Moreover, for MMA-MAPC1 copolymers, it is obvious that the theoretical curves fit quite well the experimental tendency: for example, sumHRC decreases quickly when comonomer content increases from 0 to $28 \mathrm{wt} \%$ and then becomes almost stable (Fig. 10). Calculated contributions to the flammability properties are given for the phosphonate group in both copolymers in Table 6 . 


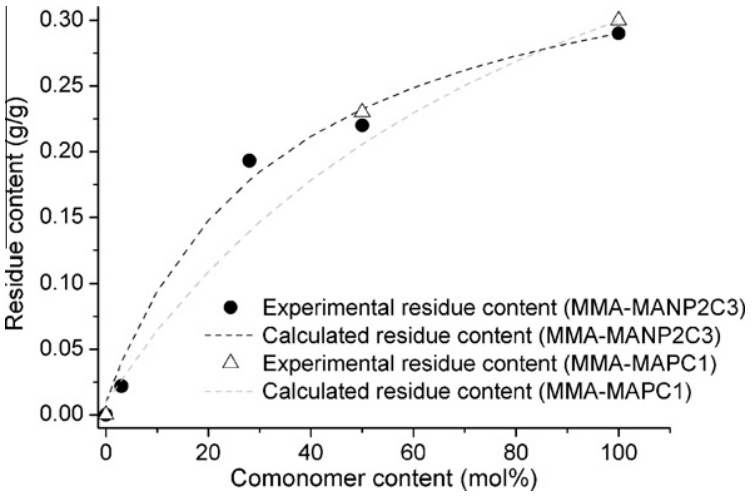

Fig. 8. Residue content versus comonomer content.

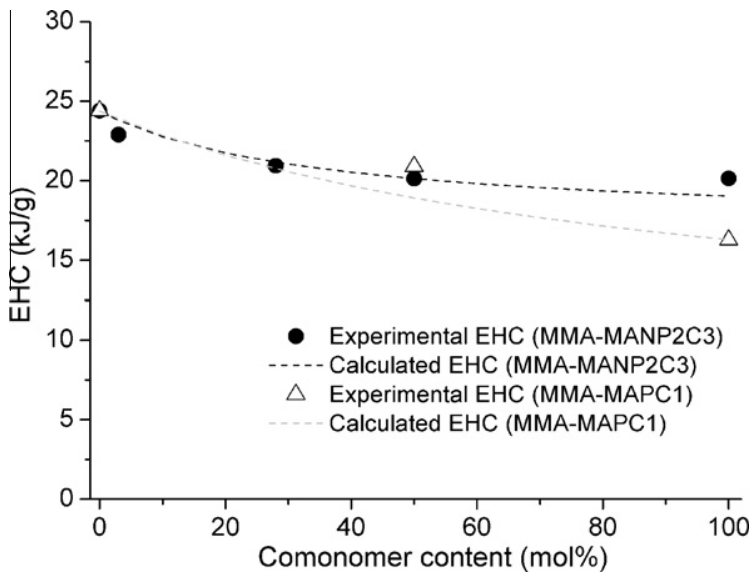

Fig. 9. EHC versus comonomer content.

Negative values are obtained for contributions to sumHRC and EHC. It means that the phosphonate group has an efficient flame retardant effect while negative values are indicative to interactions between this group and some other groups present in the polymer. EHC values for the phosphonate group in MMA-MANP2C3 is positive but lower than the contributions for other chemical groups in the molecular structure (except the ester group, see Table S2). Thus, the phosphonate group contributes to decrease this parameter value (according to the additive law of mixtures). Lastly, the residue content is significant for the phosphonate group, while other groups in the molecular structure contribute only slightly to residue content.

It should be noticed that the contributions to EHC and residue content is slightly better in the case of the copolymer (MMA-MAPC1). According to our theoretical results, we could conclude that the chemical environment of the phosphonate group has only a small influence on its contributions to EHC and residue content. On the contrary, a great difference in the contributions to sumHRC is calculated. The phosphonate group in the copolymer (MMA-MANP2C3) contributes to the decrease of sumHRC in a larger extent than the phosphonate group in the copolymer (MMA-MAPC1). This result indicates that the chemical environment influences strongly the contribution

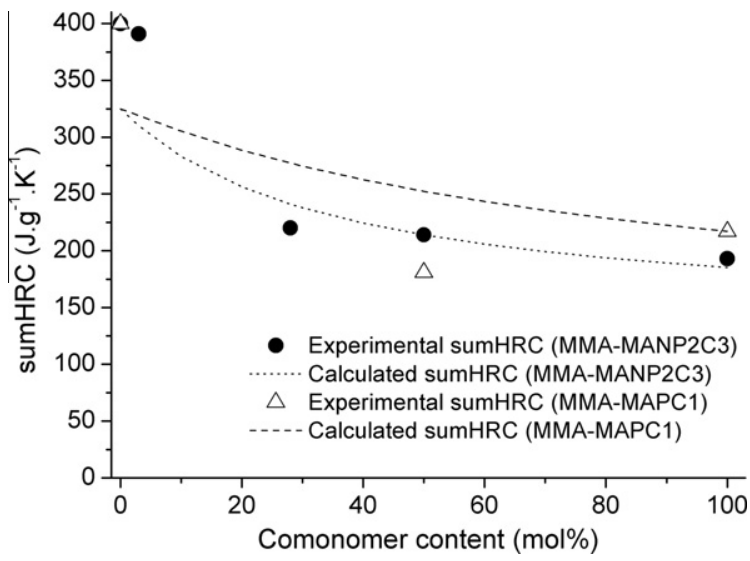

Fig. 10. sumHRC versus comonomer content.

Table 6

Contributions to sumHRC, EHC, residue content for the phosphonate group (in MMA-MAPC1 and MMA-MANP2C3).

\begin{tabular}{lll}
\hline $\begin{array}{l}\text { Contributions of the phosphonate } \\
\text { group to: }\end{array}$ & $\begin{array}{l}\text { MMA- } \\
\text { MAPC1 }\end{array}$ & $\begin{array}{l}\text { MMA- } \\
\text { MANP2C3 }\end{array}$ \\
\hline sumHRC $\left(\mathrm{Jg}^{-1} \mathrm{~K}^{-1}\right)$ & -258 & -549 \\
EHC $\left(\mathrm{kJg}^{-1}\right)$ & -0.75 & 4.7 \\
Residue content $\left(\mathrm{gg}^{-1}\right)$ & 0.78 & 0.7 \\
\hline
\end{tabular}

to sumHRC of the phosphonate group, contrary to the hypothesis of "non-interacting groups" in the simplified approach proposed by Lyon et al. [5]. Moreover, HRC is directly related to the peak of heat release rate, which is the most important single parameter to assess a fire hazard. Thus choosing the best chemical environment is the first important parameter to optimize the flame retardancy effect of the phosphonate group.

\section{Conclusions}

Two phosphorus modified PMMA were investigated. Both empirical and theoretical studies revealed the better flame retardancy effect of phosphonate group, in both condensed and vapor phase, in copo.(MMA-MAPC1) compared to that of copo.(MMA-MANP2C3). It seems that the simultaneous presence of phosphorus and nitrogen does not necessarily lead to a synergistic effect and the weakness of $\mathrm{P}-\mathrm{C}-\mathrm{N}$ bond, compared to $\mathrm{P}-\mathrm{N}$ bond, may explain the absence of synergistic effect. The better efficiency of phosphorus in copo.(MMA-MAPC1) compared to that of copo.(MMA-MANP2C3) can be due to accessibility of phosphonate group to react with ester group of MMA part. It seems that the claw like conformation of copo.(MMAMANP2C3) may decrease these interactions because phosphonate groups interact preferentially between themselves. The theoretical approach showed that the sumHRC is more influenced by the chemical environment of phosphorus than other parameters (EHC and residue). The interesting properties of copo.(MMA-MAPC1) in term of flammability, as well as the maintaining of transparency, associated to the ease of its synthesis may allow to be commercialized on large scale. 


\section{Acknowledgment}

We thank Mr. Jean-Marie Taulemesse for assistance with the SEM/EDX analysis.

\section{Appendix A. Supplementary data}

Supplementary data associated with this article can be found, in the online version, at doi:10.1016/ j.eurpolymj.2011.12.015.

\section{References}

[1] Price D, Pyrah K, Hull TR, Milnes GJ, Ebdon JR, Hunt BJ, et al. Flame retarding poly(methyl methacrylate) with phosphorus-containing compounds: comparison of an additive with a reactive approach Polym Degrad Stab 2001;74(3):441-7.

[2] Price D, Pyrah K, Hull TR, Milnes GJ, Ebdon JR, Hunt BJ, et al. Flame retardance of poly(methyl methacrylate) modified with phosphoruscontaining compounds. Polym Degrad Stab 2002;77(2):227-33.

[3] Joseph P, Tretsiakova-Mcnally S. Reactive modifications of some chain- and step-growth polymers with phosphorus-containing compounds: effects on flame retardance-a review. Polym Adv Technol 2011;22(4):395-406

[4] Vahabi H, Longuet C, Ferry L, David G, Robin JJ, Lopez-Cuesta JM. Effect of aminobisphosphonated copolymer on the thermal stability and flammability of poly(methyl methacrylate), Polym Int 2011, doi: $10.1002 /$ pi.3158.

[5] Lyon RE, Takemori MT, Safronava N, Stoliarov SI, Walters RN. A molecular basis for polymer flammability. Polymer 2009;50(12): 2608-17.
[6] El Asri Z, Chougrani K, Negrell-Guirao C, David G, Boutevin B, Loubat C. An efficient process for synthesizing and hydrolyzing a phosphonated methacrylate: investigation of the adhesive and anticorrosive properties. Polym Sci: Part A: Polym Chem 2008;46(14):4794-803.

[7] Chougrani K, Boutevin B, David G, Boutevin B. New N,N-aminodiphosphonate-containing methacrylic derivatives, their syntheses and radical copolymerizations with MMA. Eur Polym J 2008;44(6):1771-81.

[8] Kashiwagi T, Inaba A, Brown JE, Hatada K, Kitayama T, Masuda E. Effects of weak linkages on the thermal and oxidative degradation of poly(methyl methacrylates). Macromolecules1986;19(8):21602168.

[9] Manring LE, Sogah DY, Cohen GM. Thermal degradation of poly(methyl methacrylate). 3. Polymer with head-to-head linkages. Macromolecules 1989;22(12):4652-4.

[10] Peterson JD, Vyazovkin S, Wight CA. Stabilizing effect of oxygen on thermal degradation of poly(methyl methacrylate). Macromol Rapid Commun 1999;20(9):480-3.

[11] Ferriol M, Gentilhomme A, Cochez M, Oget N, Mieloszynski JL. Thermal degradation of poly(methyl methacrylate) (PMMA) modelling of DTG and TG curves Polym Degrad Stab 2003;79(2):271-281

[12] Wilkie CA. TGA/FTIR: an extremely useful technique for studying polymer degradation. Polym Degrad Stab 1999;66(3):301-6.

[13] Leu TS, Wang CS. Synergistic effect of a phosphorus-nitrogen flame retardant on engineering plastics. J Appl Polym Sci 2004;92(1):410-7.

[14] Gaan S, Sun G, Hutches K, Engelhard MH. Effect of nitrogen additives on flame retardant action of tributyl phosphate: phosphorusnitrogen synergism. Polym Degrad Stab 2008;93(1):99-108.

[15] Walters RN, Lyon RE. Molar group contributions to polymer flammability. J Appl Polym Sci 2003;87(3):548-63.

[16] Van Krevelen DW. Properties of Polymers (3rd ed.), Amsterdam: Elsevier, 1990 (chapter 6). 